\title{
High-intensity interval training for chronic pain conditions: a narrative review
}

\author{
Riccardo Maria Botta', Stefano Palermi², Domiziano Tarantino ${ }^{2, *}$ \\ ${ }^{1}$ Anesthesia and Intensive Care, Department of Medical and Surgical Science, Magna Graecia University, Catanzaro, Italy \\ ${ }^{2}$ Department of Public Health, University of Naples Federico II, Naples, Italy
}

Chronic pain is defined as pain that persists past the normal healing time. Physical activity and exercise programs are increasingly being promoted and used for a variety of chronic pain conditions. Evidence suggests that physical exercise is an intervention with few adverse events that may improve pain severity and physical function, thus improving the quality of life. High-intensity interval training (HIIT) has been shown to improve physical outcome measures and to decrease disorder-related disability in people with chronic disorders. Since an overview of the benefits of HIIT on chronic pain conditions has not been published yet, this review aims to report the effects of HIIT alone or in combination with other forms of training on different kind of chronic pain conditions. A search in the main scientific electronic databases was performed. The results of the studies included in this review showed that HIIT is beneficial for several chronic pain conditions, improving pain and physical function. Since HIIT could represent a valid help to conventional drug therapies, it could improve the quality of life of these subjects. The actual quality of evidence remains very low, and further high evidence studies are needed to confirm the promising outcomes reported in this review.

Keywords: High-intensity interval training, Exercise, Training, Pain, Chronic pain conditions

\section{INTRODUCTION}

The International Association for the Study of Pain defines pain as "an unpleasant sensory or emotional experience associated with actual or potential tissue damage" (Treede et al., 2015). Chronic pain is defined as pain that persists past the normal healing time, usually for at least three months. Chronic pain affects about $20 \%$ of people worldwide, accounting for $20 \%$ of physician visits, and representing a significant burden on healthcare costs (Treede et al., 2015). According to the International Classification of Diseases-11, chronic pain conditions are divided into seven categories: chronic primary pain, chronic cancer pain, chronic post-traumatic and post-surgical pain, chronic neuropathic pain, chronic headache and orofacial pain, chronic visceral pain and chronic musculoskeletal pain (Treede et al., 2015).

Chronic pain management requires a multidisciplinary approach that includes pharmacological therapy, physical therapy, interven- tional approach and psychological therapy (Treede et al., 2015).

For many years, the treatment of choice for chronic pain included recommendations for rest and inactivity. However, exercise may have specific advantages in reducing the severity of chronic pain, also improving overall physical and mental health, and physical functioning. Physical activity and exercise programs are increasingly being promoted and offered in various healthcare systems for a variety of chronic pain conditions. Evidence suggests that physical exercise is an intervention with few adverse events that may improve pain severity and physical function, thus improving the quality of life (Geneen et al., 2017).

Since many of the most common causes of chronic pain cannot be fully treated, it is critical to understand that routine exercise (usually a combination of aerobic and resistance training) may not only help preventing some of those causes, but that it was also proven to be effective in alleviating some of the most neuropathy-related distressing symptoms (Dobson et al., 2014; Wonders et al.,
${ }^{*}$ Corresponding author: Domiziano Tarantino (iD https://orcid.org/0000-0003-1570-9568 Department of Public Health, University of Naples Federico II, Via Sergio Pansini nr. 5, 80131 Naples, Italy Email: domiziano22@gmail.com

Received: December 30, 2021 / Accepted: January 10, 2022
This is an Open Access article distributed under the terms of the Creative Commons Attribution Non-Commercial License (https://creativecommons.org/licenses/by-nc/4.0/) which permits unrestricted non-commercial use, distribution, and reproduction in any medium, provided the original work is properly cited. 
2013). For example Tai Chi, that is a kind of Chinese martial art, has been proposed to relief symptoms related to chronic pain conditions (Dobson et al., 2014; Hung et al., 2009; Kong et al., 2016; Palermi et al., 2020; Peng, 2012).

High-intensity interval training (HIIT) has been recently recognized as one of the most popular fitness trend worldwide: it involves short bursts of very intense activity interspersed by short periods of rest or low-intensity exercises (MacInnis and Gibala, 2017). HIIT represents a valid alternative to moderate-intensity continuous training (MICT), which is the recommended gold standard in several guidelines (Garber et al., 2011; Santos et al., 2020; Thum et al., 2017). While continuous exercise at high intensity leads to exhaustion soon, the alternation of high intensity with rest or low-to-moderate intensity blocks allows patients to easily achieve high intensity levels (Palermi et al., 2021). Furthermore, HIIT has been proposed as a time-efficient form of exercise that may overcome motivational barriers associated with traditional MICT (Fleg, 2016).

Several studies have demonstrated the effectiveness of HIIT on both healthy and pathological subjects (Gibala et al., 2012; Wen et al., 2019). Moreover, HIIT has been shown to improve physical outcome measures, such as exercise capacity and muscle strength, and to decrease disorder-related disability in people with different chronic disorders (Ross et al., 2016) such as multiple sclerosis (Farup et al., 2016), human immunodeficiency virus-induced distal symmetrical polyneuropathy (Maharaj and Yakasai, 2018), chronic obstructive pulmonary disease (Gloeckl et al., 2013; Kortianou et al., 2010), diabetes (Karstoft et al., 2013; Palermi et al., 2021; Terada et al., 2016), and cardio-metabolic diseases (Freyssin et al., 2012; Weston et al., 2014).

Given all these benefits related to HIIT, and since an overview of the effects of HIIT on chronic pain conditions has not been published yet, there is the need to report what are the advantages, but also the disadvantages, related to its practice. Therefore, the aim of this review is to report the results of the studies that evaluated the benefits of HIIT alone or in combination with other forms of training on different kind of chronic pain conditions.

\section{MATERIALS AND METHODS}

Given the paucity of the available literature on the main topic of the present study, the authors decided that a narrative review would be more suitable for publication. All the procedures related to this review were organized and reported after performing a search in the main scientific electronic databases (Springerlink, MED-
LINE, PubMed, CINAHL, Web of Science, Scopus, Cochrane CENTRAL, and PEDro) to identify the available scientific articles about the effects of HIIT on chronic pain conditions. Only articles that assessed the outcomes of HIIT on humans (alone or in combination with other types of training) on different chronic pain conditions were selected. Other articles that reported the outcomes of HIIT (for example on animals or in vitro) on chronic pain conditions were reported in the discussion section of the present manuscript. The results of the research lead to the selection of eight articles: two about the effects of HIIT on fibromyalgia, two on chronic nonspecific low back pain, one on type-II diabetes related musculoskeletal pain, one on persistent pain in woman with a story of traumatic stress, one on pain sensitivity in women undergoing chemotherapy for breast cancer, and one on axial spondylarthritis.

\section{RESULTS}

A summary of the outcomes of the selected studies is reported in Table 1.

\section{Fibromyalgia}

Fibromyalgia (FM) is a complex syndrome characterized by chronic widespread pain, unrefreshing sleep, fatigue, and cognitive dysfunction. FM affects about $5 \%$ of adults, primarily women between 20 and 60 years of age. The pathophysiology of FM is still unclear, but central sensitization was recognized as the main mechanism involved, and it is characterized by central augmentation of sensory input. The aetiology of the central sensitization in FM is still debated: some studies underlined the involvement of immune system (proinflammatory chemokines/cytokines) (Bradley, 2009), others a neuroendocrine system dysfunction (hypothalamic-pituitary-adrenal axis) (Theoharides et al., 2019). Many short- and medium-term studies highlighted the relative efficacy of physical training on pain and other symptoms related to FM (Bidonde et al., 2014). Two recent studies evaluated the effects of HIIT on FM.

A pilot randomized controlled trial (RCT) by Atan and Karavelioğlu (2020) enrolled 60 women to a 6-week program of exercise. Patients were randomly assigned to three groups: HIIT plus strengthening and stretching exercises, MICT plus strengthening and stretching exercises, and control. The HIIT program consisted of five training sessions per week of 35 min each, performed using cycle-ergometers. Each session consisted of a 5-min warmup period cycling at $50 \%$ of maximum heart rate (HRmax), then four sets of 4-min high-intensity intervals at $80 \%-95 \%$ of HRmax interspersed with three sets of 3-min active recovery intervals 
Table 1. Summary of clinical evidence examining the impact of HIIT on chronic pain conditions

\begin{tabular}{|c|c|c|c|c|c|c|}
\hline Study and authors & Diagnosis & Condition groups & $\begin{array}{l}\text { Exercise } \\
\text { duration }\end{array}$ & $\begin{array}{c}\text { Exercise session } \\
\text { (frequency and duration) }\end{array}$ & Exercise intensity & Outcomes \\
\hline $\begin{array}{l}\text { Atan and Karavelioğlu } \\
\text { (2020) }\end{array}$ & Fibromyalgia & HIIT vs. MICT vs. Control & 6 Weeks & $\begin{array}{l}5 \text { days/wk } \\
35 \text { min }\end{array}$ & 80\%-95\% HRmax & $\begin{array}{l}\uparrow \text { Quality of life } \\
\uparrow \text { Functional capacity } \\
\downarrow \text { Pain }\end{array}$ \\
\hline Bodéré et al. (2020) & Fibromyalgia & $\begin{array}{l}\text { Active (initially MICT and } \\
\text { then HIIT), semiactive, } \\
\text { passive }\end{array}$ & 5 Years & $\begin{array}{l}3 \text { days/wk } \\
45 \text { min }\end{array}$ & 85\%-110\% HRmax & $\begin{array}{l}\uparrow \text { Quality of life } \\
\uparrow \text { Quality of sleep } \\
\downarrow \text { Pain } \\
\downarrow \text { Anxiety } \\
\downarrow \text { Depression }\end{array}$ \\
\hline Cox et al. (2020b) & $\begin{array}{l}\text { Type II diabetes related } \\
\text { neuropathic pain }\end{array}$ & $\begin{array}{l}\text { C-HIIT vs. UC } \\
\text { C-MICT vs. UC }\end{array}$ & 8 Weeks & $\begin{array}{l}3 \text { days/wk } \\
26 \text { min }\end{array}$ & 85\%-95\% HRmax & $\downarrow$ Pain \\
\hline Sveaas et al. (2020) & Axial spondyloarthritis & HIIT vs. no-intervention & 12 Weeks & 3 days/wk & ND & $\begin{array}{l}\downarrow \text { Pain } \\
\downarrow \text { Fatigue } \\
\downarrow \text { Stiffness } \\
\downarrow \text { Inflammation }\end{array}$ \\
\hline Flehr et al. (2019) & Traumatic stress & HIIT vs. Bikram yoga & 8 Weeks & $\begin{array}{l}3 \text { days/wk } \\
45 \text { min }\end{array}$ & ND & $\downarrow$ Pain \\
\hline Verbrugghe et al. (2019) & $\begin{array}{l}\text { Chronic nonspecific low } \\
\text { back pain }\end{array}$ & HIIT vs. MICT & 12 Weeks & $\begin{array}{l}2 \text { days/wk } \\
90 \mathrm{~min}\end{array}$ & ND & $\begin{array}{l}\uparrow \text { Functional capacity } \\
\uparrow \text { Exercise capacity } \\
\uparrow \text { Back strength } \\
\downarrow \text { Disability } \\
\downarrow \text { Pain }\end{array}$ \\
\hline Verbrugghe et al. (2019) & $\begin{array}{l}\text { Chronic nonspecific low } \\
\text { back pain }\end{array}$ & $\begin{array}{c}\text { HIITSTRE vs. HIITSTAB vs. } \\
\text { HIITCOM vs. HIITMOB }\end{array}$ & 12 Weeks & $\begin{array}{l}2 \text { days/wk } \\
90 \mathrm{~min}\end{array}$ & ND & $\begin{array}{l}\uparrow \text { Functional capacity } \\
\uparrow \text { Exercise capacity } \\
\uparrow \text { Back strength } \\
\downarrow \text { Disability } \\
\downarrow \text { Pain }\end{array}$ \\
\hline Mijwel et al. (2018) & Breast cancer & $\begin{array}{l}\text { RT-HIIT vs. UC } \\
\text { AT-HIIT vs. UC }\end{array}$ & 16 Weeks & $\begin{array}{l}2 \text { days/wk } \\
60 \text { min }\end{array}$ & RPE of 16-18 & $\begin{array}{l}\downarrow \text { Fatigue } \\
\downarrow \text { Pain-hypersensitivity } \\
\uparrow \text { Muscle strength }\end{array}$ \\
\hline
\end{tabular}

HIIT, high-intensity interval training; MICT, moderate-intensity continuous training; HRmax, maximum heart rate; C-HIIT, combined high-intensity interval training; C-MICT, combined moderate-intensity continuous training; UC, usual care; ND, not defined; HIITSTRE, high-intensity general resistance training; HIITSTAB, high-intensity core strength training; HIITCOM, high-intensity general resistance and core strength program; HIITMOB, high-intensity general resistance and mobility exercises; RT-HIIT, concurrent resistance and high-intensity interval training; AT-HIIT, concurrent moderate-intensity aerobic and high-intensity interval training; RPE, rating of perceived exertion.

at $70 \%$ of HRmax, and 5 min of cool down cycling at $50 \%$ of HRmax.

The authors found that their exercise protocols (30 sessions per week of HIIT or MICT plus strengthening and stretching exercises) had some benefits on disability, pain degree, functional capacity, and quality of life in the treatment of FM. However, contrary to the hypothesis of the authors, HIIT was not superior to MICT. A prospective observational longitudinal study by Bodéré et al. (2020) investigated the effects of a specific cardio training program lasting five years on pain and quality of life in patients with FM. One hundred and thirty-eight women with FM were recruited for the study and were asked to carry out three sessions of MICT per week, each lasting $45 \min$ (64\%-75\% HRmax). During the first year, the patients progressively increased their training intensity, and, during the last 2 years, patients were asked to associate MICT with HIIT (at 85\%-90\% HRmax). Session training was performed with 20 min of biking (warm-up, 55\%-65\% HRmax), 20 min of elliptical trainer (before the third year, progressively $20 \mathrm{~min}$ of MICT at 64\%-75\% HRmax; after the third year, 10 min of MICT followed by $10 \mathrm{~min}$ of HIIT), and 5 min of recovery on the treadmill (55\%-65\% HRmax). The authors found that this combination of trainings, associated with multidisciplinary care, alleviated pain, anxiety, and depression, and improved both quality of life and quality of sleep.

\section{Chronic nonspecific low back pain}

Chronic nonspecific low back pain (CNSLBP) is one of the most common musculoskeletal disorders affecting men and women of all age groups (Airaksinen et al., 2006). Up to 85\% of chronic low back pain cases are nonspecific, with no clear underlying patho- 
anatomical cause (Verbrugghe et al., 2020). Even though exercise therapy is an important and frequently applied part of multidisciplinary treatment of CNSLBP, overall therapy effects remain low (Koes et al., 2010).

Two recent RCTs by Verbrugghe et al. $(2019,2020)$ evaluated the effects of a HIIT program with a similar MICT program on disability, pain, function, exercise capacity, and abdominal and back muscle strength in patients with CNSLBP.

The first RCT in 2019 (Verbrugghe et al., 2019) included 38 patients with CNSLBP that was not attributable to a recognized specific pathology. Participants were randomly assigned to an experimental group performing HIIT or to a group performing MICT. The HIIT protocol consisted of a cardiorespiratory training using a cycle ergometer (5-min warm-up, then five 1-min bouts separated by one minute of active rest, with cycling bouts increasing every two sessions by $10 \mathrm{sec}$ ), general resistance training (three upper body and three lower body exercises, one set of a maximum of 12 repetitions performed at the $80 \%$ of 1-repetition maximum for each exercise, and then the workload was progressively increased using a 5\% progression scale), and core muscle training (six static core exercises were performed, one set of 10 repetitions of a 10-sec static hold, and then exercise difficulty was increased). The authors stated that HIIT proved to be a feasible, well tolerated, and effective therapy modality in CNSLBP. Moreover, it showed greater improvements on disability and exercise capacity than MICT.

The second RCT in 2020 (Verbrugghe et al., 2020) evaluated the effectiveness of different HIIT exercise modalities, and compared the outcomes of these modalities to find the best therapeutic interventions for patients with CNSLBP. The study included 80 patients with CNSLBP, and participants were randomly assigned to one of the four experimental groups performing high-intensity cardiorespiratory interval training coupled with: (a) high-intensity general resistance training; (b) high-intensity core strength training; (c) combined high-intensity general resistance and core strength program; (d) mobility exercises. Trunk mobility exercises consisted of six exercises aimed to improve the mobility of the trunk and hip complex. All the other adopted exercise protocols were the same as the previous work by the same group of study (Verbrugghe et al., 2019).

The results of the second study showed that all four HIIT groups had considerable clinically relevant improvements, so the cardiorespiratory HIIT in all the forms included in the study was found to effectively improve CNSLBP rehabilitation. For this reason, the author suggested that HIIT can be combined with other therapy modalities when setting up exercise therapy protocols for CNSLBP rehabilitation (Verbrugghe et al., 2020).

\section{Type-Il diabetes related musculoskeletal pain}

Long-standing peripheral neuropathic pain associated with peripheral neuropathy occurs in one of six diabetic subjects. Chronic painful diabetic peripheral neuropathy can cause symptoms that last for years, severely impairing functional activities, and consequently the quality of life (Cox et al., 2020b; Daousi et al., 2004). The benefits of physical exercise for the prevention and management of type-II diabetes are well established (Palermi et al., 2020), but there is little knowledge on the specific effects of exercise training on chronic pain for this condition (Cox et al., 2020a).

A recent preliminary RCT by Cox et al. (2020b) evaluated the safety and efficacy of HIIT on inactive people with type-II diabetes. Thirty-two inactive adults with type-II diabetes were randomised to supervised combined MICT (C-MICT), supervised combined HIIT (C-HIIT), or control group, for 8 weeks. Potential participants were included in the study if they had medically diagnosed type-II diabetes with a glycosylated hemoglobin level of $6.0 \%$ or a fasting glucose level of $7.0 \mathrm{mmol} / \mathrm{L}$ at baseline testing. Furthermore, one quarter of participants were classified as obese class 1 (moderate), $28 \%$ as class 2 (severe), and $16 \%$ as class 3 (very severe). C-HIIT trained three times per week with each session incorporating a warm-up (and cool down) for three minutes at $50 \%-60 \%$ HRmax, followed by four minutes of high-intensity aerobic exercise at 85\%-95\% HRmax, and eight per 1-min intervals of high-intensity resistance exercise at a rating of perceived exertion (RPE) of $\geq 17$ (very hard). One minute of rest separated each interval. Participants assigned to C-HIIT had a greater reduction in musculoskeletal pain intensity than those allocated to the control group, while reduction in pain intensity was not significantly different for participants allocated to C-MICT compared to control group. Anyway, no changes were observed on self-reported neuropathy symptoms and sensory function between C-HIIT and control, and C-MICT and control.

The authors stated that their preliminary RCT supported the efficacy and safety of C-HIIT and C-MICT for reducing musculoskeletal pain in inactive individuals with type-II diabetes. Anyway, no effect of exercise training on self-reported neuropathy symptoms or sensory function was detected (Cox et al., 2020b).

\section{Persistent pain following a trauma}

Chronic pain is closely associated with traumatic stress outcomes, particularly posttraumatic stress disorder (McFarlane, 2010; Morasco et al., 2013; Powers et al., 2014; Yehuda et al., 2015). Yoga has been proposed as a kind of treatment, and the current trauma sensitive yoga and yoga for pain programs emphasize a gentle ap- 
proach to the practice in an effort to promote relaxation and movement confidence in a minimally confronting way (Cramer et al., 2013; Della Valle et al., 2020; Flehr et al., 2019; Posadzki et al., 2011; Price et al., 2017; van der Kolk et al., 2014). These programs have several limitations and lack of comparable forms of exercise (Cramer et al., 2013). For this reason, the aim of the pilot RCT by Flehr et al. (2019) was to provide preliminary evidence of efficacy, and to assess the feasibility, of two types of vigorous exercise (Bikram yoga and HIIT) as sensorimotor retraining/exposure therapies to improve persistent pain severity and interference in women with persistent pain and a history of trauma.

Thirty-four women with a persistent pain condition and a selfreported history of trauma (physiological and/or psychological), were recruited. Inclusion criteria was a score more than five at the Brief Pain Inventory (Poquet and Lin, 2016). HIIT training was performed three times per week, for 8 weeks. The HIIT formula consisted of four workout formats: (a) time (i.e., complete the circuit as fast as possible); (b) tabata (i.e., interval training utilising 8 exercises followed by a cardio burst); (c) reps (i.e., do a maximum reps or load in a set time); (d) box (i.e., 12 min to complete as many rounds as possible of the 4 cross training stations followed by a cardio burst). All these HIIT classes were taught by certified gym instructors and before starting them, participants were required to attend a functional training assessment with a certified trainer to introduce all the HIIT workout formats.

The authors stated that women with persistent pain and a history of trauma undertaking an 8-week, 3-class per week vigorous exercise intervention reported improved levels of persistent pain. No differences in pain levels between the Bikram yoga and the HIIT group were seen, so no conclusions about the efficacy of Bikram yoga compared to HIIT for persistent pain could be made (Flehr et al., 2019).

\section{Pain sensitivity and physical function in women undergoing chemotherapy for breast cancer}

The most reported symptom during and after treatment for breast cancer is cancer-related fatigue (CRF), a multifactorial distress which together with treatment-induced pain contributes to physiological dysfunction (Davis and Walsh, 2010). Exercise interventions for patients undergoing curative breast cancer therapy have been well tolerated and have shown positive effects on CRF, physical function, and chemotherapy-induced peripheral neuropathy (Furmaniak et al., 2016; Wonders et al., 2013).

A RCT by Mijwel et al. (2018) compared the effects of concurrent resistance and HIIT (RT-HIIT) or concurrent moderate-in- tensity aerobic and HIIT (AT-HIIT), or usual care (control group), on pain sensitivity and physiological outcomes in patients with breast cancer during chemotherapy. Two hundred and forty women were randomized to 16 weeks of RT-HIIT, AT-HIIT, or usual care. RT-HIIT group completed both resistance and high-intensity interval exercise during each session. Participants performed two or three sets of 8-12 repetitions at an intensity of $80 \%$ of the patients' estimated 1-repetition maximum. The AT-HIIT group commenced with 20 min of moderate-intensity continuous aerobic exercise at a RPE of 13-15 on the Borg scale (Borg, 1982). Both RT-HIIT and AT-HIIT concluded with three $x$ three minutes bouts of HIIT at an RPE of 16-18 interspersed with one minute of recovery.

The authors found that RT-HIIT provided significant beneficial effects in terms of counteracting cancer-related physical and total fatigue, reducing anthracycline-induced pain-hypersensitivity, and improving muscle strength. Moreover, the RT-HIIT intervention was as efficient as AT-HIIT in maintaining body mass and cardiorespiratory fitness in women with early breast cancer receiving adjuvant chemotherapy (Mijwel et al., 2018).

\section{Pain and disability in patients with axial spondyloarthritis}

The most important features of the axial spondyloarthritis (axSpA) (i.e. a chronic inflammatory rheumatic disease) are inflammatory back pain, reduced joint mobility and disability (Sieper and Poddubnyy, 2017). Exercise has a crucial role in the management for patients with inflammatory rheumatic diseases, and low dose exercises are commonly used to relieve pain and increase joint mobility (Dagfinrud et al., 2011; Rausch Osthoff et al., 2018; Regel et al., 2017). However, exercise has a small beneficial effect on those disease activity (Dagfinrud et al., 2008; Dagfinrud et al., 2011; Regel et al., 2017; Sveaas et al., 2017). A recent RCT by Sveaas et al. (2020) examined the effects of a 12-week HIIT training on disease activity and cardiovascular health in patients with axSpA.

One hundred patients with axSpA were randomly assigned to the HIIT group or to a no-intervention control group. The inclusion criteria were, among the others, the fulfilment of the Assessment of SpondyloArthritis International Society criteria for axSpA (Rudwaleit et al., 2009), and moderate to high disease activity at prescreening (according to the Bath ankylosing spondylitis Disease Activity Index) (Garrett et al., 1994).

The HIIT group followed the American College of Sports Medicine recommendations for cardiorespiratory and muscular strength exercises (Garber et al., 2011), and lasted for 12 weeks. Two times per week the sessions were supervised by a physiotherapist and 
consisted of HIIT cardiorespiratory and strength exercises. In addition, the exercise group performed an individual cardiorespiratory exercise session once a week. In total, the intervention group had three training sessions per week.

The authors stated that HIIT reduced disease symptoms (pain, fatigue, stiffness), and inflammation in patients with axSpA. It also improved patients' function and cardiovascular health. The authors also stated that future studies should examine the effects of longer exercise interventions with longer follow-up, and that it is also time to refine the HIIT programme in clinical practice (Sveaas et al., 2020).

\section{DISCUSSION}

HIIT has been recently recognized as one of the most popular fitness trends worldwide, and it has been shown to have the potential to decrease disorder-related disability in people with different chronic disorders (Ross et al., 2016). The results of this review showed that HIIT is beneficial for several chronic pain conditions: for this reason, it could represent a valid help to conventional drug therapies and can be useful to improve the quality of life of patients who suffer from those conditions. Chronic pain has become a widespread condition that negatively impact the lives of patients (Hadi et al., 2019). It is often due to hardly treatable life-lasting diseases, with which patients must learn to live with. Even when there is only one precipitating event in the genesis of chronic pain, a series of factors that affect the duration, intensity, and effects of it, still remain (Mills et al., 2019). Conditions like FM, low-back pain or diabetes are common examples of these long-lasting chronic diseases. Given the complex nature of these conditions, a multidisciplinary treatment approach is often the winning choice (Kawai et al., 2017), and physical activity represents one of the cornerstones of complementary feasible therapies.

Physical activity has great advantages for patients with chronic pain, since it has no interactions with multiple drugs they usually use (Geneen et al., 2017). Furthermore, exercise may have specific benefits in reducing the severity of chronic pain, as well as more general benefits associated with improved overall physical and mental health, as depression (Finan and Smith, 2013), physical deconditioning (Bousema et al., 2007), and obesity (Bigal and Rapoport, 2012), that are commonly observed in these subjects. This positive effect of exercise on chronic pain can be explained from a microscopic point of view, such as an increase of the production of endogenous opioids that could lead to transient antinociception (Stagg et al., 2011).
For example, Belmonte et al. (2018) highlighted how HIIT has an antihyperalgesic effect on mices with chronic pain. In these mouse models with induced chronic postischemia pain, lumbar spinal cord tissue expression of tumor necrosis factor-alpha, interleukin-12, and phosphorylated extracellular signal-regulated kinases (ERK) 1/2 (that are mediators involved in inflammatory response) was less in the HIIT group than in the control group. Inhibition of ERK induced by interval running could be mediated by adenosine, cannabinoids, and opioids that are released during physical exercise. HIIT increases expression of peroxisome proliferator-activated receptor gamma coactivator-1-alpha promoting mitochondrial biogenesis with a relevant impact on oxidative capacity, antioxidant defence, glucose uptake, resistance to age-related sarcopenia and anti-inflammatory pathways (de Araujo et al., 2016). This analgesic effects of HIIT was also assessed in a study on humans by Kodesh and Weissman-Fogel, who also stated that the hypoalgesic effect was more consistent in the HIIT than in the MICT group (Kodesh and Weissman-Fogel, 2014).

The improvement related to HIIT could be explained also by macroscopic changes: it can improve overall and site-specific muscle strength and muscle cross-sectional area (Agten et al., 2021; Sabag et al., 2018), and this could impact positively outcomes of low back pain (de Sousa et al., 2019); it can improve joint range of motion and flexibility (Jiménez-García et al., 2019), potentially leading to a decrease in balance impairments in diabetic patients (Francois and Little, 2015); it can improve cardiorespiratory fitness (Ross et al., 2016), potentially mitigating chemotherapy side effects (Ferioli et al., 2018). Therefore, the interest of HIIT in exercise prescription in the scientific literature is growing. Even if HIIT led to an important decrease in pain in all the selected articles for this review, in some of them no significant difference with MICT were observed (Cox et al., 2020a).

Moreover, as frequently observed in the scientific literature, the specific type of recommended HIIT remains unclear: for example, both Mijwel et al. (2018) and Verbrugghe et al. (2020) stated that different forms of HIIT could be equally beneficial, alone or combined with other types of training. The main limitation of this review is the very small number of articles found in the available scientific literature about the effects of HIIT on chronic pain conditions. Furthermore, almost all the reported exercise protocols differ from each other, so it is not possible to draw definitive conclusion about which protocol provides the best benefits. For these reasons, given the promising results of the articles included in this review, more research should be conducted on the effects of HIIT for patients with chronic pain condition, but this could only be 
possible if HIIT will be considered as an effective therapeutic exercise program for patients with chronic pain conditions. A wise prescription and an effective supervision are two essential features when talking about "therapeutic" HIIT. Furthermore, also the "dark" side effects of HIIT (such as high rate of perceived effort, rapid changes in blood pressure and heart rate, hyperventilation, muscle soreness, high rate of injury, etc.) should be taken into account, especially when prescribing it in frail subjects (Joisten et al., 2022). For this reason, physical activity should be tailored to each individual, with an accurate prescription from the physician in dose and range (Luan et al., 2019). Neuromuscular training and prestrengthening programs could be helpful for novel subjects beginning to train (Rynecki et al., 2019).

In conclusion, it is possible to state that HIIT showed promising results as a therapeutic exercise for patients with chronic pain condition. The actual quality of evidence remains very low, and further high evidence studies (such as RCTs) are needed to confirm the promising outcomes reported in this review.

\section{CONFLICT OF INTEREST}

No potential conflict of interest relevant to this article was reported.

\section{ACKNOWLEDGMENTS}

The authors received no financial support for this article.

\section{REFERENCES}

Agten A, Verbrugghe J, Stevens S, Eijnde BO, Timmermans A, Vandenabeele F. High intensity training increases muscle area occupied by type II muscle fibers of the multifidus muscle in persons with non-specific chronic low back pain: a pilot trial. Appl Sci 2021;11:3306.

Airaksinen O, Brox JI, Cedraschi C, Hildebrandt J, Klaber-Moffett J, Kovacs F, Mannion AF, Reis S, Staal JB, Ursin H, Zanoli G; COST B13 Working Group on Guidelines for Chronic Low Back Pain. Chapter 4. European guidelines for the management of chronic nonspecific low back pain. Eur Spine J 2006;15 (Suppl 2):S192-300.

Atan T, Karavelioğlu Y. Effectiveness of high-intensity interval training vs moderate-intensity continuous training in patients with fibromyalgia: a pilot randomized controlled trial. Arch Phys Med Rehabil 2020;101: 1865-1876.

Belmonte LAO, Martins TC, Salm DC, Emer AA, de Oliveira BH, Mathias K, Goldim MP, Horewicz VV, Piovezan AP, Bobinski F, Petronilho F,
Martins DF. Effects of different parameters of continuous training and high-intensity interval training in the chronic phase of a mouse model of complex regional pain syndrome type I. J Pain 2018;19:1445-1460.

Bidonde J, Busch AJ, Bath B, Milosavljevic S. Exercise for adults with fibromyalgia: an umbrella systematic review with synthesis of best evidence. Curr Rheumatol Rev 2014;10:45-79.

Bigal ME, Rapoport AM. Obesity and chronic daily headache. Curr Pain Headache Rep 2012;16:101-109.

Bodéré C, Cabon M, Woda A, Giroux-Metges MA, Bodéré Y, Saliou P, Quinio B, Misery L, Le Fur-Bonnabesse A. A training program for fibromyalgia management: a 5-year pilot study. SAGE Open Med 2020; 8:2050312120943072.

Borg GA. Psychophysical bases of perceived exertion. Med Sci Sports Exerc 1982;14:377-381.

Bousema EJ, Verbunt JA, Seelen HAM, Vlaeyen JWS, Knottnerus AJ. Disuse and physical deconditioning in the first year after the onset of back pain. Pain 2007;130:279-286.

Bradley LA. Pathophysiology of fibromyalgia. Am J Med 2009;122(12 Suppl):S22-30.

Cox ER, Coombes JS, Keating SE, Burton NW, Coombes BK. Not a painless condition: rheumatological and musculoskeletal symptoms in type 2 diabetes, and the implications for exercise participation. Curr Diabetes Rev 2020a;16:211-219.

Cox ER, Gajanand T, Burton NW, Coombes JS, Coombes BK. Effect of different exercise training intensities on musculoskeletal and neuropathic pain in inactive individuals with type 2 diabetes - preliminary randomised controlled trial. Diabetes Res Clin Pract 2020b;164:108168.

Cramer H, Lauche R, Haller H, Dobos G. A systematic review and metaanalysis of yoga for low back pain. Clin J Pain 2013;29:450-460.

Dagfinrud H, Halvorsen S, Vøllestad NK, Niedermann K, Kvien TK, Hagen KB. Exercise programs in trials for patients with ankylosing spondylitis: do they really have the potential for effectiveness? Arthritis Care Res 2011;63:597-603.

Dagfinrud H, Kvien TK, Hagen KB. Physiotherapy interventions for ankylosing spondylitis. Cochrane Database Syst Rev 2008;2008:CD002822.

Daousi C, MacFarlane IA, Woodward A, Nurmikko TJ, Bundred PE, Benbow SJ. Chronic painful peripheral neuropathy in an urban community: a controlled comparison of people with and without diabetes. Diabet Med 2004;21:976-982

Davis MP, Walsh D. Mechanisms of fatigue. J Support Oncol 2010;8:164174.

de Araujo GG, Papoti M, Dos Reis IG, de Mello MA, Gobatto CA. Short and long term effects of high-intensity interval training on hormones, metabolites, antioxidant system, glycogen concentration, and aerobic performance adaptations in rats. Front Physiol 2016;7:505. 
de Sousa CS, de Jesus FLA, Machado MB, Ferreira G, Ayres IGT, de Aquino LM, Fukuda TY, Gomes-Neto M. Lower limb muscle strength in patients with low back pain: a systematic review and meta-analysis. J Musculoskelet Neuronal Interact 2019;19:69-78.

Della Valle E, Palermi S, Aloe I, Marcantonio R, Spera R, Montagnani S, Sirico F. Effectiveness of workplace yoga interventions to reduce perceived stress in employees: a systematic review and meta-analysis. J Funct Morphol Kinesiol 2020;5:33.

Dobson JL, McMillan J, Li L. Benefits of exercise intervention in reducing neuropathic pain. Front Cell Neurosci 2014;8:102.

Farup J, Dalgas U, Keytsman C, Eijnde BO, Wens I. High intensity training may reverse the fiber type specific decline in myogenic stem cells in multiple sclerosis patients. Front Physiol 2016;7:193.

Ferioli M, Zauli G, Martelli AM, Vitale M, McCubrey JA, Ultimo S, Capitani S, Neri LM. Impact of physical exercise in cancer survivors during and after antineoplastic treatments. Oncotarget 2018;9:14005-14034.

Finan PH, Smith MT. The comorbidity of insomnia, chronic pain, and depression: dopamine as a putative mechanism. Sleep Med Rev 2013;17: 173-183.

Fleg JL. Salutary effects of high-intensity interval training in persons with elevated cardiovascular risk. F1000Res 2016;5:F1000 Faculty Rev-2254.

Flehr A, Barton C, Coles J, Gibson SJ, Lambert GW, Lambert EA, Dhar AK, Dixon JB. \#MindinBody - feasibility of vigorous exercise (Bikram yoga versus high intensity interval training) to improve persistent pain in women with a history of trauma: a pilot randomized control trial. BMC Complement Altern Med 2019;19:234.

Francois ME, Little JP. Effectiveness and safety of high-intensity interval training in patients with type 2 diabetes. Diabetes Spectr 2015;28:39-44.

Freyssin C, Verkindt C, Prieur F, Benaich P, Maunier S, Blanc P. Cardiac rehabilitation in chronic heart failure: effect of an 8-week, high-intensity interval training versus continuous training. Arch Phys Med Rehabil 2012;93:1359-1364.

Furmaniak AC, Menig M, Markes MH. Exercise for women receiving adjuvant therapy for breast cancer. Cochrane Database Syst Rev 2016;9: CD005001.

Garber CE, Blissmer B, Deschenes MR, Franklin BA, Lamonte MJ, Lee IM, Nieman DC, Swain DP, American College of Sports Medicine. American College of Sports Medicine position stand. Quantity and quality of exercise for developing and maintaining cardiorespiratory, musculoskeletal, and neuromotor fitness in apparently healthy adults: guidance for prescribing exercise. Med Sci Sports Exerc 2011;43:1334-1359.

Garrett S, Jenkinson T, Kennedy LG, Whitelock H, Gaisford P, Calin A. A new approach to defining disease status in ankylosing spondylitis: The Bath Ankylosing Spondylitis Disease Activity Index. J Rheumatol 1994; 21:2286-2291.
Geneen LJ, Moore RA, Clarke C, Martin D, Colvin LA, Smith BH. Physical activity and exercise for chronic pain in adults: an overview of Cochrane Reviews. Cochrane Database Syst Rev 2017;4:CD011279.

Gibala MJ, Little JP, Macdonald MJ, Hawley JA. Physiological adaptations to low-volume, high-intensity interval training in health and disease. J Physiol 2012;590:1077-1084.

Gloeckl R, Marinov B, Pitta F. Practical recommendations for exercise training in patients with COPD. Eur Respir Rev 2013;22:178-186.

Hadi MA, McHugh GA, Closs SJ. Impact of chronic pain on patients' quality of life: a comparative mixed-methods study. J Patient Exp 2019;6: 133-141.

Hung JW, Liou CW, Wang PW, Yeh SH, Lin LW, Lo SK, Tsai FM. Effect of 12-week tai chi chuan exercise on peripheral nerve modulation in patients with type 2 diabetes mellitus. J Rehabil Med 2009;41:924-929.

Jiménez-García JD, Hita-Contreras F, de la Torre-Cruz M, Fábrega-Cuadros R, Aibar-Almazán A, Cruz-Díaz D, Martínez-Amat A. Risk of falls in healthy older adults: benefits of high-intensity interval training using lower body suspension exercises. J Aging Phys Act 2019;27:325-333.

Joisten N, Gehlert S, Zimmer P. Is high-intensity interval training harmful to health? Trends Endocrinol Metab 2022;33:85-86.

Karstoft K, Winding K, Knudsen SH, Nielsen JS, Thomsen C, Pedersen BK, Solomon TP. The effects of free-living interval-walking training on glycemic control, body composition, and physical fitness in type 2 diabetic patients: a randomized, controlled trial. Diabetes Care 2013; 36:228-236

Kawai K, Kawai AT, Wollan P, Yawn BP. Adverse impacts of chronic pain on health-related quality of life, work productivity, depression and anxiety in a community-based study. Fam Pract 2017;34:656-661.

Kodesh E, Weissman-Fogel I. Exercise-induced hypoalgesia - interval versus continuous mode. Appl Physiol Nutr Metab 2014;39:829-834.

Koes BW, van Tulder M, Lin CWC, Macedo LG, McAuley J, Maher C. An updated overview of clinical guidelines for the management of nonspecific low back pain in primary care. Eur Spine J 2010;19:2075-2094.

Kong LJ, Lauche R, Klose P, Bu JH, Yang XC, Guo CQ, Dobos G, Cheng YW. Tai Chi for chronic pain conditions: a systematic review and meta-analysis of randomized controlled trials. Sci Rep 2016;6:25325.

Kortianou EA, Nasis IG, Spetsioti ST, Daskalakis AM, Vogiatzis I. Effectiveness of interval exercise training in patients with COPD. Cardiopulm Phys Ther J 2010;21:12-19.

Luan X, Tian X, Zhang H, Huang R, Li N, Chen P, Wang R. Exercise as a prescription for patients with various diseases. J Sport Health Sci 2019; 8:422-441.

MacInnis MJ, Gibala MJ. Physiological adaptations to interval training and the role of exercise intensity. J Physiol 2017;595:2915-2930.

Maharaj SS, Yakasai AM. Does a rehabilitation program of aerobic and 
progressive resisted exercises influence HIV-induced distal neuropathic pain? Am J Phys Med Rehabil 2018;97:364-369.

McFarlane AC. The long-term costs of traumatic stress: intertwined physical and psychological consequences. World Psychiatry 2010;9:3-10.

Mijwel S, Backman M, Bolam KA, Olofsson E, Norrbom J, Bergh J, Sundberg CJ, Wengström Y, Rundqvist H. Highly favorable physiological responses to concurrent resistance and high-intensity interval training during chemotherapy: the OptiTrain breast cancer trial. Breast Cancer Res Treat 2018;169:93-103.

Mills SEE, Nicolson KP, Smith BH. Chronic pain: a review of its epidemiology and associated factors in population-based studies. Br J Anaesth 2019;123:e273-e283.

Morasco BJ, Lovejoy TI, Lu M, Turk DC, Lewis L, Dobscha SK. The relationship between PTSD and chronic pain: mediating role of coping strategies and depression. Pain 2013;154:609-616.

Palermi S, Iacono O, Sirico F, Modestino M, Ruosi C, Spera R, De Luca M. The complex relationship between physical activity and diabetes: an overview. J Basic Clin Physiol Pharmacol 2021 Sep 29 [Epub]. https:// doi.org/10.1515/jbcpp-2021-0279.

Palermi S, Sacco AM, Belviso I, Marino N, Gambardella F, Loiacono C, Sirico F. Effectiveness of Tai Chi on balance improvement in type 2 diabetes patients: a systematic review and meta-analysis. J Aging Phys Act 2020;28:787-797.

Peng PW. Tai chi and chronic pain. Reg Anesth Pain Med 2012;37:372-382.

Poquet N, Lin C. The Brief Pain Inventory (BPI). J Physiother 2016;62:52.

Posadzki P, Ernst E, Terry R, Lee MS. Is yoga effective for pain? A systematic review of randomized clinical trials. Complement Ther Med 2011; 19:281-287.

Powers A, Fani N, Pallos A, Stevens J, Ressler KJ, Bradley B. Childhood abuse and the experience of pain in adulthood: the mediating effects of PTSD and emotion dysregulation on pain levels and pain-related functional impairment. Psychosomatics 2014;55:491-499.

Price M, Spinazzola J, Musicaro R, Turner J, Suvak M, Emerson D, van der Kolk B. Effectiveness of an extended yoga treatment for women with chronic posttraumatic stress disorder. J Altern Complement Med 2017;23:300-309.

Rausch Osthoff AK, Niedermann K, Braun J, Adams J, Brodin N, Dagfinrud $\mathrm{H}$, Duruoz T, Esbensen BA, Günther KP, Hurkmans E, Juhl CB, Kennedy N, Kiltz U, Knittle K, Nurmohamed M, Pais S, Severijns G, Swinnen TW, Pitsillidou IA, Warburton L, Yankov Z, Vliet Vlieland TPM. 2018 EULAR recommendations for physical activity in people with inflammatory arthritis and osteoarthritis. Ann Rheum Dis 2018; 77:1251-1260

Regel A, Sepriano A, Baraliakos X, van der Heijde D, Braun J, Landewé R, Van den Bosch F, Falzon L, Ramiro S. Efficacy and safety of non-phar- macological and non-biological pharmacological treatment: a systematic literature review informing the 2016 update of the ASAS/EULAR recommendations for the management of axial spondyloarthritis. RMD Open 2017;3:e000397.

Ross LM, Porter RR, Durstine JL. High-intensity interval training (HIIT) for patients with chronic diseases. J Sport Health Sci 2016;5:139-144.

Rudwaleit M, van der Heijde D, Landewé R, Listing J, Akkoc N, Brandt J, Braun J, Chou CT, Collantes-Estevez E, Dougados M, Huang F, Gu J, Khan MA, Kirazli Y, Maksymowych WP, Mielants H, Sørensen IJ, Ozgocmen S, Roussou E, Valle-Oñate R, Weber U, Wei J, Sieper J. The development of Assessment of SpondyloArthritis international Society classification criteria for axial spondyloarthritis (part II): validation and final selection. Ann Rheum Dis 2009;68:777-783.

Rynecki ND, Siracuse BL, Ippolito JA, Beebe KS. Injuries sustained during high intensity interval training: are modern fitness trends contributing to increased injury rates? J Sports Med Phys Fitness 2019;59:1206-1212.

Sabag A, Najafi A, Michael S, Esgin T, Halaki M, Hackett D. The compatibility of concurrent high intensity interval training and resistance training for muscular strength and hypertrophy: a systematic review and meta-analysis. J Sports Sci 2018;36:2472-2483.

Santos A, Lonsdale C, Lubans D, Vasconcellos D, Kapsal N, Vis-Dunbar M, Jung ME. Rates of compliance and adherence to high-intensity interval training in insufficiently active adults: a systematic review and meta-analysis protocol. Syst Rev 2020;9:56.

Sieper J, Poddubnyy D. Axial spondyloarthritis. Lancet 2017;390:73-84.

Stagg NJ, Mata HP, Ibrahim MM, Henriksen EJ, Porreca F, Vanderah TW, Philip Malan T Jr. Regular exercise reverses sensory hypersensitivity in a rat neuropathic pain model: role of endogenous opioids. Anesthesiology 2011;114:940-948.

Sveaas SH, Bilberg A, Berg IJ, Provan SA, Rollefstad S, Semb AG, Hagen $K B$, Johansen MW, Pedersen E, Dagfinrud H. High intensity exercise for 3 months reduces disease activity in axial spondyloarthritis (axSpA): a multicentre randomised trial of 100 patients. Br J Sports Med 2020;54:292-297.

Sveaas SH, Smedslund G, Hagen KB, Dagfinrud H. Effect of cardiorespiratory and strength exercises on disease activity in patients with inflammatory rheumatic diseases: a systematic review and meta-analysis. Br J Sports Med 2017;51:1065-1072.

Terada T, Wilson BJ, Myette-Côté E, Kuzik N, Bell GJ, McCargar LJ, Boulé NG. Targeting specific interstitial glycemic parameters with high-intensity interval exercise and fasted-state exercise in type 2 diabetes. Metabolism 2016;65:599-608.

Theoharides TC, Tsilioni I, Bawazeer M. Mast cells, neuroinflammation and pain in fibromyalgia syndrome. Front Cell Neurosci 2019;13:353.

Thum JS, Parsons G, Whittle T, Astorino TA. High-intensity interval train- 
ing elicits higher enjoyment than moderate intensity continuous exercise. PLoS One 2017;12:e166299.

Treede RD, Rief W, Barke A, Aziz Q, Bennett MI, Benoliel R, Cohen M, Evers S, Finnerup NB, First MB, Giamberardino MA, Kaasa S, Kosek E, Lavand'homme P, Nicholas M, Perrot S, Scholz J, Schug S, Smith $\mathrm{BH}$, Svensson P, Vlaeyen JWS, Wang SJ. A classification of chronic pain for ICD-11. Pain 2015;156:1003-1007.

van der Kolk BA, Stone L, West J, Rhodes A, Emerson D, Suvak M, Spinazzola J. Yoga as an adjunctive treatment for posttraumatic stress disorder: a randomized controlled trial. J Clin Psychiatry 2014;75:e559-565.

Verbrugghe J, Agten A, Stevens S, Hansen D, Demoulin C, Eijnde BO, Vandenabeele F, Timmermans A. High intensity training to treat chronic nonspecific low back pain: effectiveness of various exercise modes. J Clin Med 2020;9:2401.

Verbrugghe J, Agten A, Stevens S, Hansen D, Demoulin C, Eijnde BO, Vandenabeele F, Timmermans A. Exercise intensity matters in chronic nonspecific low back pain rehabilitation. Med Sci Sports Exerc 2019; 51:2434-2442.

Wen D, Utesch T, Wu J, Robertson S, Liu J, Hu G, Chen H. Effects of different protocols of high intensity interval training for $\mathrm{VO}_{2}$ max improvements in adults: a meta-analysis of randomised controlled trials. J Sci Med Sport 2019;22:941-947.

Weston KS, Wisløff, U, Coombes JS. High-intensity interval training in patients with lifestyle-induced cardiometabolic disease: a systematic review and meta-analysis. Br J Sports Med 2014;48:1227-1234.

Wonders KY, Whisler G, Loy H, Holt B, Bohachek K, Wise R. Ten weeks of home-based exercise attenuates symptoms of chemotherapy-induced peripheral neuropathy in breast cancer patients. Health Psychol Res 2013;1:e28.

Yehuda R, Hoge CW, McFarlane AC, Vermetten E, Lanius RA, Nievergelt CM, Hobfoll SE, Koenen KC, Neylan TC, Hyman SE. Post-traumatic stress disorder. Nat Rev Dis Primers 2015;1:15057. 